\title{
Discouraged finance seekers: An analysis of Australian small and medium-sized enterprises
}

\author{
Dong Xiang \\ Griffith University, Australia \\ Andrew C. Worthington \\ Griffith University, Australia
}

Helen Higgs

Griffith University, Australia

\begin{abstract}
Using the Business Longitudinal Database compiled by the Australian Bureau of Statistics, this paper investigates the effects of firm-level factors, including size, profitability, the number of employees, business strategy, and life-cycle, on finance seeking (debt and/or equity) by Australian small and medium-sized enterprises (SMEs). We identify firms seeking and not seeking finance and firms successfully and unsuccessfully acquiring finance over a three-year period. Taking advantage of the longitudinal nature of our data, we examine how past finance-seeking experience affects future finance-seeking behaviour. We find that experience as a discouraged finance seeker significantly affects future finance-seeking behaviour. This has important policy implications in that the observed demand for finance by SMEs and the capital rationing implied may understate the actual level because potential finance seekers do not apply for finance in anticipation of rejection. We also find that SMEs become relatively more discouraged in seeking debt than equity finance.
\end{abstract}

\section{Keywords}

SMEs, financing decisions, debt and equity, discouraged finance seekers 


\section{Introduction}

A voluminous literature already considers the restricted ability of small and medium-sized enterprises (SMEs) to obtain external finance, largely because of their inherent informational opacity (Beck et al., 2005; Berger and Udell, 2006; Beck et al., 2008; Guiso and Minetti, 2010). This directly results in a distinct lack of SME financing opportunities in securitised debt and equity markets (Beck et al., 2005; Beck et al., 2008; Guiso and Minetti, 2010), with the external finance that is available primarily in an indirect form (bank loans and trade credit) (Iturralde et al., 2010; Newman et al., 2010). Moreover, given the lack of external financing sources, SMEs the world over also tend to rely heavily on internal sources of finance (such as retained earnings and accruals). Consequently, there is a consensus that SMEs can be severely capital rationed through supply side factors largely stemming from the information asymmetry between themselves and potential lenders or investors.

However, the lack of suitable access to external finance also potentially results from the unwillingness of SME owners to seek such finance given suboptimal business goal setting (Vos et al., 2007). For example, SMEs may favour profit stability over profit maximization (Hamelin, 2011), may not consider growth as a key objective (Vos et al., 2007), or can lack the entrepreneurial or managerial resources necessary to develop business plans when seeking finance. More mundanely, SMEs may be simply unaware of what type of financing is appropriate in the circumstances (Berger and Schaeck, 2011). Lastly, SMEs are often very concerned about the risk of losing control and decision-making power (Psillaki and Daskalakis, 2009). These capital structure-determining factors differ markedly across small and large firms and these demand-side factors make the financing behaviour of SMEs of considerable interest in its own right.

In this paper, we argue that in the process of finance seeking by SMEs, a situation we refer to as the discouraged finance seeker may arise. The basic premise of the discouraged finance seeker is that SMEs do not seek finance, even if needed, because they believe an application or request for finance (either debt or equity) will be unsuccessful given experience. Fortunately, several existing studies already focus on discouraged borrowers, whereby businesses require debt finance but do not choose to apply because they believe (sometimes erroneously given their credit worthiness) that they will be turned down by banks or other lenders (Jappelli, 1990; Cavalluzzo et al., 2002; Kon and Storey, 2003; Chakravarty and Yilmazer, 2009). 
In this analysis, we broaden the concept of the discouraged borrower (debt only) to that of a discouraged finance seeker (debt and/or equity). In doing so, we contribute to this important literature in a number of ways. First, we argue that SMEs may not only be discouraged in applying for debt, but also equity, including private equity and venture capital, for two main reasons. First, unlike creditors, investors may suffer from agency problems such as hold-up issues arising from the SME reneging on investments (Neher, 1999). Therefore, investors may design stricter screening processes or devices, such as staged investments, or rely on elaborate formal contracts and incentives to help mitigate risk (Bergemann and Hege, 2003; Cornelli and Yosha, 2003; Dahiya and Ray, 2012). However, this "neoclassical contracting” tends to erode the trust of entrepreneurs in their equity backers (Stratling et al., 2013). As a result, agency problems make SMEs access to external equity difficult and expensive because of the screening and monitoring role of external equity providers (Del-Palacio et al., 2012). Concomitantly, SMEs may be equally discouraged in seeking equity finance.

Second, there are possible substitution effects between equity funding and lending because SMEs may turn to equity markets when faced with a credit rejection (Amini et al., 2013). SMEs may also attempt to avoid the rent-extracting behaviour of banks by seeking finance elsewhere (Berger and Schaeck, 2011). Therefore, an investigation into finance seeking more broadly can more accurately describe the extent of discouragement found among SMEs. To our best knowledge, this is the first analysis to extent the concept of a discouraged borrower to that of a discouraged finance seeker for both debt and equity. Third, we investigate the firm-level determinants of financing decisions by Australian SMEs by making allowance for both the cross-sectional factors that affect financing-seeking behaviour and the time-series outcomes of experiences with finance seeking in the past. By using a lagged regression model, we alleviate the problems of both selection bias and endogeneity recurrent in the literature on finance-seeking behaviour, and appropriately recognise the temporal dimension of financeseeking decisions.

Fourth, ours is also the first analysis to combine firm-level factors and the concept of discouraged finance seekers when analysing SME finance-seeking behaviour. This helps us disentangle the impact of apparently rational and irrational behaviour in deciding not only which SMEs do or do not require finance, but also which SMEs require finance, but through experience do not apply. If this holds, then the number of SMEs that unsuccessfully attempt to seek external finance through the various stages of the business cycle may understate the actual, as at least SMEs that would ordinarily seek finance simply do not. 
Fifth, we also place considerable emphasis on not only commonly observed firm-level factors affecting financing-seeking behaviour, such as size, profitability, export orientation and industry, but also the firm's declared business strategy. This is important because SMEs may set incomplete or suboptimal business goal or objectives, which can contribute to the unwillingness or lack of motivation of SME owners in seeking external finance. In addition, business strategy is also likely to be included in business plans given to the potential providers of external finance, and therefore we can gauge how these factors are 'priced' in finance-granting decisions. Once again, there is little work of this type in the literature.

The remainder of the paper is organized as follows. The second section reviews the relevant literature and discusses the concept of the discouraged finance seeker. The third and fourth sections respectively provide details of the data and model specification. The fifth section discusses the results, and the sixth section provides some concluding remarks.

\section{Analytical framework}

A substantial literature concerns the process of credit rationing arising from asymmetric information between borrowers and lenders, such that lenders find it difficult to determine whether a borrower is creditworthy and hence do not extend finance. Consequently, in equilibrium, there may be an insufficient supply of loans. For example, using a dataset drawn from the 1983 US Survey of Consumer Finances, Jappelli (1990) noted that the incidence of discouraged borrowers varied across demographic groups. Japelli (1990) suggested that this would lead to lower biased estimates of the probability that consumers are credit constrained because of the process of self-selection. Put differently, the incidence of credit constraints found among borrowers would appear less severe.

Using data from the 1993 US National Survey of Small Business Finances, Cavalluzzo et al. (2002) later attempted to deal with these selection biases (Heckman, 1979) through use of a joint model of the apply and denied a loan decision. Following Heckman's (1976) twostage procedure, Chakravarty and Yilmazer (2009) subsequently employed a multi-stage model to explore relationship banking among SMEs. The extent of discouraged borrowing is evident in both of these surveys. For example, in the US Survey of Consumer Finances, 322 households (about 10.8\% of the respondents), responded “yes” to the question about being a discouraged borrower (though only 129 or $40 \%$ of these respondents were actually denied a loan). Similarly, in the US National Survey of Small Business Finances, nearly 50\% of finance-desiring SMEs reported that they feared denial. As discussed, we extend the concept 
of discouraged borrowers to that of discouraged finance seekers by also include seekers of equity finance. Following Cole (2010), we essentially consider the question of "who needs finance” and "who gets finance."

\section{$<$ FIGURE 1 HERE $>$}

As shown in Figure 1, we can model the finance-seeking process of firms into a sequence of steps. In period $t$, given operating and financial conditions, a firm makes a decision about whether to seek finance. For those firms that decide to seek finance, two outcomes are possible, they are either successful or they are unsuccessful. The financing outcomes from period $t$ then affect the conditions of firms seeking finance in period $t+1$. For the firms that were successful in obtaining finance in period $t$, they again make future finance-seeking decisions based on their existing operating and financial conditions. However, for firms denied finance in period $t$, previous denial may also affect the decision about whether to seek finance. The result is that these firms, which would otherwise apply for finance given their operating and financial conditions, do not apply. We refer to these firms, shaded in Figure 1, as discouraged finance seekers.

While the analytical framework in Figure 1 appears simple at first, several complications require attention to make it empirically tractable. The discouraged finance-seeker concept from which it derives describes the phenomenon whereby an otherwise finance-worthy firm does not apply for finance given expectations of possible rejection and/or higher application costs and/or higher costs of capital (Beck et al., 2005; Berger and Udell, 2006). Problematically, a SME may not seek finance because it does not actually require finance or because it is discouraged from applying for finance. That is, it can be difficult to distinguish between SMEs that do not need finance and SMEs that need finance but do not apply because they are discouraged.

To address this issue, it is necessary to impose some assumptions regarding observed behaviour. For instance, Kon and Storey (2003) restricted the non-applications of discouraged borrowers to those that faced high application costs arising from bank screening error. As mentioned earlier, our SMEs are potentially not only discouraged borrowers, but also can be discouraged in seeking external equity such as private equity and venture capital. To deal with risk in SMEs, investors design screening processes or rely on elaborate formal contracts and incentives. As a result, agency problems make SMEs access to external equity both difficult and expensive. Therefore, our first proposition is that SMEs may not only be discouraged borrowers, but also discouraged in seeking equity, which we jointly term 
discouraged finance seeking. An investigation into discouraged finance seekers can therefore enhance our knowledge of discouraged borrowing, which is generally more common given that debt is a typical source of finance for SMEs, by controlling for substitution effects between debt and equity among SMEs.

Several issues arise when investigating SME financing behaviour. First, as SMEs differ from large firms in terms of business operations (Ang, 1991), business objectives may closely relate to the need for external finance by SMEs. In particular, propositions related to profit maximization can limit the validity of any attempt to investigate the factors involved in SME financing decisions. For example, Hamelin (2011) concludes that SMEs tend to promote profit stability rather than profit maximization. Further, most SMEs appear to be managed in such a way as to minimize intrusion in their business, so debt is often preferred to equity because of the lower risk of losing control and decision-making power (Psillaki and Daskalakis, 2009). Moreover, SMEs sometimes appear to be unaware of which particular type of financing is most appropriate (Berger and Schaeck, 2011). However, with the exception of Matthews et al. (1994), (Romano et al., 2000) and Vos et al. (2007), there is little existing work on the effects of business objectives on SME finance behaviour.

Second, an accurate understanding of discouraged financing should also involve considerations of creditworthiness. Levenson and Willard (2000) first argued that a comprehensive definition of credit rationing should take into account the connection between creditworthy firms that apply but fail to obtain finance, and otherwise creditworthy firms that decide not to apply for finance, given expectations about how long it may take to obtain financing. However, assessing the worthiness of finance applicants can be difficult, not least for SMEs. For a start, unlike large listed firms, there are no publicly available credit rankings for SMEs. In addition, finance worthiness can relate more to the subjective judgements of in moneylender than the characteristics of the borrower (Moro et al., 2012). In addition, especially in SMEs, relationship banking based on soft information normally acts as the main channel between firms and their lenders or creditors (Berger and Udell, 2006).

Consequently, even observed finance worthiness can reflect the subjective judgement of a lending manager than an objective assessment of a firm's innate credit-relevant characteristics. For example, Moro et al. (2012) find that banks charge lower interest rates if the loan managers perceive the entrepreneurs to be competent. Drawing on these perspectives, we establish our second proposition that controlling for the characteristics of SMEs, such as business objectives and creditworthiness, which can affect financing behaviour, is essential when examining the phenomenon of discouraged finance seekers. 
Third, self-selection can contaminate the sample of firms applying for finance, i.e. firms that are more likely to have their application rejected are less likely to apply. For instance, as shown in Figure 1, the firms that make a decision to seek finance in period $t$ could be firms that received finance and were therefore not discouraged in the period before period $t$ (period $t-1$ not shown). To address this issue, some studies have used Heckman's two-stage approach including a selection equation in the first stage (Chakravarty and Yilmazer, 2009; Brown et al., 2011). Furthermore, concerned about the least squares requirement in the second stage of Heckman's approach, Cole (2010) employs a univariate probit model in the first stage and a bivariate probit model in the second and third stages.

In our analysis, we specify a lagged logistic model with denial of finance proxying for the discouraged finance seeker. We justify this specification as follows. First, because of their constrained ability to seek finance, we assume an SME denied finance is technically more likely to face a finance crunch, thus would need finance in the following year, notwithstanding the discouraged finance-seeker effect. The survey we use provides some evidence for this where in responding as to the reason(s) for seeking finance, $37.5 \%$ of firms said it was for maintaining short-term cash flow or liquidity and 39.5\% for the replacement of current equipment and machinery (emphasis added). However, only $23.9 \%$ of firms responded that it was for new equipment or machinery and $7.6 \%$ for the purchase of new information technology hardware or software (multiple responses permitted). This suggests most SMEs were seeking finance to maintain existing business operations instead of funding future investment. We can only expect that these funding pressures intensified thereafter.

Second, self-selection could contaminate the sample of SMEs that require finance in period $t$. However, if the firms supposed to be less likely to be discouraged in period $t-1$ are found to be discouraged in period $t+1$ because of denial in period $t$, discouraged finance seekers exist. Third, we include a large number of control variables including profitability, firm age and size, and business strategy, to control for finance worthiness as it is unobservable. Finally, we employ a lagged model to address the practical challenges arising from both self-selection and endogeneity (Blumberg and Letterie, 2008).

\section{Data}

We utilize the surveys included in the Business Longitudinal Database (BLD) Expanded Confidentialised Unit Record File (CURF) conducted periodically by the Australian Bureau of Statistics (ABS). The ABS directly collects the data with the assistance of the Australian 
Taxation Office and Australian Customs. Overall, the BLD aims to increase the understanding of the activities or factors that are relevant to business performance and the business characteristics associated with these activities and factors.

The BLD comprises two independent samples (referred to as panels) drawn from the population of Australian SMEs, defined in the survey as businesses employing fewer than 200 persons. The panel used in this analysis was from a survey frame created in June 2005, which represented the population of some 1.5 million Australian SMEs with a sample of 2,732 SMEs. The SMEs in the panel were surveyed each year over the financial years 200405, 2005-06, and 2006-07 (we refer to these by the ending calendar year, i.e. 2005, 2006, and 2007, respectively).

However, dropouts (firms deciding not to participate further in the survey) and firm failures could potentially cause the problem of survivorship in the sample data given the incidence of missing data. Unfortunately, the survey does not identify or differentiate between these two possible reasons for missing data. That said, while, survivorship can bias the results of studies based on relatively long sample periods, our sample period is only for three years, thus we expect bias not to be a major issue. Moreover, because the SMEs that applied for finance in 2005 and failed were technically unable to apply for finance in any the following years, i.e. 2006 or 2007, the results may actually bias the results downwards. If anything, we may then actually underestimate rather than overestimate the discouraged finance-seeker effect.

\section{Model specification}

We employ a lagged regression model to investigate the phenomenon of discouraged borrowers. Using a three-year panel of data, we investigate whether finance denial in year $t+$ $n-1$ has an effect on finance seeking in year $t+n$.

\section{Applied for finance $_{t+n}=f\left(\right.$ Denied finance fint $_{t+1},{\left.\text { Control factor } s_{t+n}\right)}$}

where Applied for finance is a binary variable indicating whether the firm applied for additional finance, $t$ is the initial year (i.e. 2005), and $n$ is 1 and 2 (i.e. 2006 and 2007, respectively). Denied finance is a dummy variable that takes a value of one if the firm received a negative outcome for an application in year $t+n-1$ and zero otherwise, and Control factors is a set of explanatory variables explaining both finance seeking and finance worthiness. As the dependent variable in the equation is binary, we employ a logistic 
regression model. Our primary hypothesis is that being unsuccessful in seeking finance in a previous period or periods will exert a detrimental effect on finance seeking in the current period, all other things being equal. We hypothesise a negative coefficient.

\section{$<$ TABLE 1 HERE $>$}

Table 1 provides the definitions of the independent variables we specify as controls in our models. The first set of explanatory variables in Table 1 concern the declared business strategy of each firms. We hypothesise that business strategy helps explain both the need and motivation for seeking finance and the ability to obtain finance. For example, a more aggressive strategy of business expansion will typically require more external finance than a more passive strategy. Financers are also more likely to reward loan applications and business plans for these types of strategy by providing finance.

In the survey, there are six response options available for the question "To what extent did this business focus on the following when assessing overall business performance." The available options are financial measures (e.g. profits, sales, growth, returns on investments), cost measures (e.g. budget, cost per unit of output, inventory cost), operational measures (e.g. asset utilisation, on-time delivery), quality measures (e.g. customer satisfaction, defect rates), innovation measures (innovations, new value-added products), and human resources (e.g. job satisfaction, skills development). SMEs were able to identify more than one response to this question. We use this information to create six dummy variables (Financial focus, Cost focus, Operational focus, Quality focus, Innovation focus, Human resources focus), which take values of one for SMEs with a stated focus in that category, otherwise zero. In general, we hypothesise that declared business strategies such as Financial focus, Operational focus and Innovation focus strategies will display positive coefficients given that that they are more financially needy in their implementation and more likely to clearly signal finance worthiness to both lenders and investors. In contrast, the remaining focuses, i.e. Cost focus, Quality focus and Human resources focus, which we consider as non-profitable or non-growth benchmarks, do not have a significant and positive effect on finance seeking.

The next set of independent variables in Table 1 are eleven industry dummies used to reflect the importance of industry on firm financing patterns (Degryse et al., 2010; Romano et al., 2000; Van der Wijst, 1989). For example, Balakrishnan and Fox (1993) conclude that firm effects explain about 52\% of capital structure variation with inter-industry differences another 11\%, while Degryse et al. (2010) finds that industry is important in explaining the level of external debt among small businesses. Elsewhere, Van der Wijst (1989) observes that 
the manufacturing industry is capital intensive and requires large investments in fixed assets derived from both debt and equity while the retail sector needs relatively less short-term debt. In Australia, Romano et al. (2000) argues that firms in the services industry are less likely to use family loans, whereas family businesses in the manufacturing industry are less likely to use capital and retained profits. To reflect these and other industry level factors, we create industry dummy variables (Agriculture, Mining, Manufacturing, Construction, Wholesale trade, Retail trade, Accommodation, Transport, Communication, Property, Culture and Recreation) using the two-digit Australian and New Zealand Standard Industry Classification (ANZSIC) subdivisions (the reference category is all other industries).

The next group of independent variables are factors affecting each firm's operational characteristics (including the requirement for finance) and behaviour (including whether it applies for finance), along with the possible determinants of finance worthiness. We use the first variable, Size (measured by firm sales) to proxy a number of conditions affecting the seeking of and access to finance by SMEs. One justification is that as there is typically less market information about smaller firms, they usually seek less external finance (Psillaki and Daskalakis, 2009; Cowling et al., 2012), and when they do, mainly short-term borrowing (Garcia-Teruel and Martinez-Solano, 2007). Tax considerations may especially be of less concern for smaller SMEs because they are unlikely to generate large profits and therefore less likely to use debt as the dominant source of finance for tax shield purposes (Pettit and Singer, 1995; Newman et al., 2010). For these reasons, we hypothesise a positive relation between firm size and finance seeking.

We also include firm age to control for the finance seeking and worthiness of the firm, being dummy variables indicating the time since establishment of the trading enterprise, namely, Operating < 5 years (start-up and early stage), Operating 10-20 years (mature stage) and Operating > 20 years (old stage). The reference category is operating 5-10 years (growth stage). This is a similar categorisation as in Berger and Udell (1998). In general, we hypothesise that start-up and early-stage SMEs have great difficulty in actually obtaining finance because of information asymmetries and potential agency problems related to the lack of a trading history. The lack of collateralisable assets can also exacerbate the problem of restricted access to finance (Bhaird and Lucey, 2010). However, the firm typically becomes more finance worthy as it moves through the growth and subsequent stages, primarily though the build-up of assets and a track record of good performance (Caneghem and Campenhout, 2010). Strengthening relationships with finance providers may also have a role to play (e.g. Newman et al., 2010; Beck et al., 2008). We hypothesise a positive coefficient. 
However, the inclusion of firm age as a variable also corresponds to the firm life-cycle and the need for finance. At the start-up and early stages, retained profits (internal equity) are scarce, and the personal resources of the owner and the number of firm connections limited. The need for finance continues to expand during the growth stage for the firm. Therefore, the need for finance is great, even though finance worthiness is not. As SMEs move into the mature and old stages, they become increasingly able to source finance from internal sources as the same time as their funding needs overall diminishes with the decline in suitable projects. We hypothesise a negative coefficient. However, as we use only a single proxy variable, the actual signs of the estimated coefficients will reflect the net effect of finance need and seeking (that decreases with firm age) and finance worthiness (that increases with firm age).

The next set of variables reflects additional dimensions of firm operations and behaviour. To start with, we can regard innovation-defined as the process of the adoption of internally or externally generated devices, systems, policies, programs, processes, products or services that are new to the adopting organization-as a proxy for growth opportunities. The influence of innovation or growth opportunities on a firm's finance decision-making has been widely discussed. This reveals that by reducing debt, firms with growth opportunities may avoid the shareholder-creditor conflict in which the benefits can transferred from shareholders to creditors (Myers, 1977; Jensen and Meckling, 1976). In addition, debt can act as a mechanism to alleviate agency cost by disciplining managers (Jensen and Meckling, 1976). Therefore, a firm with growth opportunities may be less likely to seek debt (Fama and French, 2002).

However, given the assumption that SMEs face financing constraints, those with growth opportunities are more likely to exhaust internal funds and require additional funds. In combination with the traditional concern of SMEs with control and independence, SMEs with growth opportunities may seek external debt instead of external equity. As a result, the influence of growth opportunities on SMEs finance seeking can be either negative (e.g., Heyman et al., 2008; Lopez-Gracia and Sogorb-Mira, 2008), positive (e.g., Degryse et al., 2010; Riding et al., 2010), or insignificant (see Psillaki and Daskakis, 2009). The dummy variable, New processes, takes a value of one if the business has introduced any new or significantly improved operational or organizational processes, otherwise zero. We hypothesise that the sign on the estimated coefficient for New processes will be positive (it increases both the need for finance, and hence finance seeking, and credit-worthiness as an indicator of a dynamic firm to financers). 
We also include profitability to control for the finance seeking and worthiness of the SME. On one hand, profitability is a key aspect of firm performance, indicating the operating conditions as well as the willingness of firms to seek finance (Romano et al., 2000); and helps in improving the acceptance of finance applications (Beck et al., 2008). On the other hand, regardless of pecking order theory, SMEs rely relatively heavily on internal sources of finance by exhausting retained earnings (profits) first, with trade creditors and banks being the sources of external finance (Iturralde et al., 2010; Newman et al., 2010). In this sense, profitability may be negatively correlated with external finance seeking (Bhaird and Lucey, 2010; Caneghem and Campenhout, 2010). In our study, the variable Profitability takes a value of one if the business experienced an increase in profitability over the previous year relative to its competitors. As we argue that the effectiveness of profitability as a proxy for finance worthiness outweighs that associated with pecking order theory, we hypothesise a positive coefficient for profitability.

The final two variables relate to foreign ownership and government assistance. Foreign ownership can potentially affect finance seeking and worthiness in two ways. First, overseas parent companies, which are very likely not small firms, could be the main source of finance for the subsidiaries and this reduces the need for external finance. Second, depending on the countries the parent firm operates in, country-specific conditions can affect SME access to finance (Hernandez-Canovas and Koeter-Kant, 2008). For this reason, we specify Foreign ownership as a dummy variable taking a value of one if there is any foreign ownership and zero otherwise.

Similarly, government assistance in the form of financial assistance can also influence SME finance seeking. For example, Barron et al. (2010) suggest that many SMEs rely on government sources of finance, especially during business downturns. This can reduce their need for other sources of external finance. At the same time, government assistance may help signal finance worthiness to prospective lenders and investors. For Government assistance, we specify a dummy variable that takes a value of one if the firm received any government assistance (both financial and in-kind), zero otherwise. The sign of the estimated coefficient with depend on the net effect of the decreased need for finance and the increased finance worthiness signalled with government finance.

\section{Descriptive analysis}


Table 1 provides the means and standard deviations for the variables used in the analysis. About 24.2\% of the SMEs are from the agriculture (including forestry and fishing) industry classification. The second-largest group of SMEs in the sample is in the manufacturing industry (16.2\%) while the third-largest sample group are from the wholesale trade industry (10.3\%). About 30\% of SMEs are less than five years old, and 23.3\% have been in operation for more than 20 years.

Among the sample SMEs, 41\% applied for finance in 2005 (t). Of these, 38.4\% applied for debt, $9.1 \%$ for equity, and $6.5 \%$ applied for both debt and equity. The application rates dramatically fell in the following two years $2006(t+1)$ and $2007(t+2)$ to just 19.2\% and 20.3\% for finance of both forms, $18.5 \%$ and $19.2 \%$ for debt, and 3.0\%, 3.1\% for equity, respectively. However, the rejection rate is low in all three years at just $12.0 \%, 13.1 \%$, and $13.7 \%$ for all forms of finance in 2005, 2006, and 2007, respectively. However, equity applications exhibit a higher rejection rate than debt applications, with more than a third of all equity applications rejected in each of the three sample years. Interestingly, in 2005 only $47.3 \%$ of SMEs regarded financial measures, such as profits, sales growth, and returns on investments, as a major indicator of intended business performance, and this decreased further to $40.2 \%$ in 2006. Similarly, cost measures also fell from as a declared focus from $40.3 \%$ in 2005 to $34.2 \%$ in 2006. However, the sample SMEs appear to pay increasingly more attention to quality measures, for example, the focus on customer satisfaction and defect rates increased from $34.3 \%$ in 2005 to $37.3 \%$ in 2006.

By comparison, most SMEs do not consider innovation as an important objective. Nonetheless, many SMEs introduced new goods, services, or processes during the sample period, from some $26.2 \%$ of the sample firms in 2005 to $36.3 \%$ of firms in 2006. About $12.4 \%$ of SMEs were considered (by the respondents) to be more profitable compared with their competitors in 2005 and 32.2\% observed an increase in profitability in 2006 compared with the previous year. In addition, $4.1 \%$ of the sampled SMEs had some degree of foreign ownership and about $16.2 \%$ of the SMEs received financial assistance from Australian government organizations in 2005 and 14.4\% in 2006.

\section{Estimation results}

We first consider the presence of discouraged finance seekers among SMEs by investigating the effects of finance denial on finance seeking in the years following. In the first three columns of Table 2, we test the effect of finance denial in $2006(t+1)$ on finance seeking 
(both debt and equity) in $2007(t+2)$. Columns 4-7 provide the results for the effects of finance denial in $2005(t)$ and $2006(t+1)$ on finance seeking in $2007(t+2)$. We then separately examine discouraged debt and equity finance seekers. Columns 8-10 provide the results for the effect of debt denial in 2006 on finance seeking in 2007, columns 11-13 detail the results for the effects of finance denial in 2005 and 2006 on finance seeking in 2007, and columns 14-19 include the results for equity denial in 2006 on equity seeking in 2007.

\section{<TABLE 2 HERE $>$}

Both the likelihood ratio (LR) and Wald tests suggest the overall significance of the results of the logistic regression analyses with the models explaining between $12.9 \%$ and $13.8 \%$ of the variation in finance seeking. Of these, the models for debt seeking have greater explanatory power then the models for equity seeking. Across all the models, the proxy for finance denial, debt denial, or equity denial consistently exerts a significant negative effect on finance seeking, debt seeking, and equity seeking in subsequent years. This effect also exhibits some persistence. For example, a SME that received a rejection for finance in $t+1$ (2006) was $14.8 \%$ less likely to apply for finance in $t+2$ (2007) and $14.2 \%$ less likely to apply for additional finance because of the effect of finance denial in $t$ (2005). This is after holding constant the factors posited to affect both finance seeking and approval.

As suggested, the discouragement effect is more obvious in the debt models than the equity models. Based on the marginal effects, a SME that received a rejection for debt was up to $25.3 \%$ less likely to apply for debt again in the following years. In contrast, the maximum marginal effect for equity models was just $6.4 \%$. This implies that SMEs are more likely to be discouraged in debt seeking due to credit rationing such as through screening or higher processing costs etc. than equity seeking through agency costs. However, we should note that equity seeking by SMEs is much less common than debt seeking, at least in our sample. For example, in 2007, 352 SMEs sought debt finance, but only 57 sought equity finance.

With respect to the control variables in Table 2, several of the business strategy dummies have a significant effect on finance seeking. As shown, SMEs whose focus lies on financial measures, including profits and ROA, are more likely to apply for additional finance, with the marginal effects on the probability of applying for finance ranging from $3.9 \%$ to $4.1 \%$ across the various models. This indicates that Australian SMEs that focus on financial measures are 2.9-5.4\% more likely to apply for additional finance than other SMEs. The only other business focus variable that is statistically significant across all of the regressions is quality focus. The significant negative effect of focus on quality measures, Quality focus, on finance- 
seeking decisions suggests that SMEs that focus on customer satisfaction and the minimisation of defect rates are less likely to apply for additional finance with a likelihood of between $3.0 \%$ and $3.9 \%$.

In terms of industry effects, SMEs operating in agriculture (including forestry and fishing) are more like to seek finance, as are firms in mining, manufacturing, and wholesale trade, but only in some of the models. We interpret this inconsistency as partly resulting from the unobserved effects of other factors, especially environmental factors, rather than any firmspecific factor. We can also observe this effect using the intercept item, where the large and significant values of the intercept in the three models for year $t+2$ indicate that the models had an obvious shift resulting from changes in some unobserved common factors in 2007. The deteriorating economic and financial conditions associated with the global financial crisis are an obvious candidate.

As also shown in Table 2, firm size exerts a significant and positive effect on finance seeking across all of the models, indicating that the larger the firm, the more likely it is to apply for finance. The marginal effects indicate that a $1 \%$ increase in firm size is associated with an increase of $4.5-7.7 \%$ in the likelihood of seeking finance. This indicates that larger firms have a greater demand for finance. In contrast, relative profitability, the period of establishment and exporting/importing behaviour do not appear to be significant determinants of finance seeking among SMEs.

In contrast, growth opportunities (as indicated by new processes reflecting innovation) and government assistance appear to have consistently significant positive effects across the models. First, SMEs with growth opportunities appear to have much stronger demand for finance, increasing at the margin the probability of applying for finance by $8.5-11.5 \%$. This could be because SMEs with growth opportunities are more likely to quickly exhaust internal funds and thus seek additional (external) funds (Riding et al., 2010). The positive effects of government assistance on finance seeking could be because firms that obtain government assistance are encouraged or trained in seeking non-government finance and/or because a record of government assistance can signal improved financial worthiness.

Finally, foreign ownership appears to have a negative effect on finance seeking, though not across all models. SMEs with some degree of foreign ownership are less likely to seek finance by $11.6 \%$ in the 2006 model. This appears to accord with pecking order theory, which suggests that SMEs with foreign ownership have more reliable internal funding from overseas parent companies. However, this effect is not significant in the 2007 models. 


\section{Concluding remarks}

In response to the important questions of "who needs finance," "who applied for finance," and "who needs finance but is discouraged from applying," we use a lagged logistic method to examine the determinants of the finance-seeking behaviours of Australian SMEs. After controlling for business objectives and other factors determining finance-seeking decisions, we find that SMEs are not only discouraged in seeking debt finance but also in seeking equity finance, so-called discouraged finance seekers. Based on a large dataset of individual firm records, we find that SMEs denied finance in 2005 or 2006 were $14.2 \%$ and 14.8\% less likely to apply in 2007, respectively. We also found SMEs were more discouraged in seeking debt finance than equity finance, with SMEs denied debt finance being up to $16.4-25.3 \%$ less likely to apply for debt finance in subsequent years.

In contrast, SMEs denied equity finance were only 3.2-6.4\% less likely to apply for equity finance following rejection. Overall, these results indicate that a lack of success in past finance-seeking behaviour continues to exert a significant and cumulative impact on financeseeking behaviour in the future and that the level of capital rationing commonly observed among SMEs significantly understates the problem because many firms simply do not seek finance based on bad experience. In terms of other results, larger firms with a financial or cost-focused business strategy with new processes indicating innovation and growth opportunities receiving government assistance are more likely to seek finance, while foreignowned firms with a quality focus are less likely to seek finance.

We believe the methodology in this paper does a good job of identifying finance seekers, or otherwise good credit and/or venture quality firms lacking the necessary confidence to seek finance because of a lack of past success, or genuinely discouraged finance seekers. This precludes firms that Freel et al. (2012: 415) in their analysis of discouraged borrowers in the UK describe as exhibiting a form of discouragement that “...may merely reflect high selfawareness and good judgment on the part of owners and managers-what one might call 'appropriately discouraged borrowers'”. If this is the case, by not seeking finance, these SMEs are artificially restricting the amount of capital available for worthwhile projects and thereby being suboptimal in maximising the value of the firm and owner wealth. This has broader important implications for the SME sector in terms of the diminished prospects for employment, growth, competitiveness and value-added and for a finance sector denied profitable opportunities to lend to worthy firms. 
Following Kon and Storey (2003: 46), discouraged finance seeking, as a broader conceptualisation of the discouraged borrowing phenomenon discussed there, primarily exists because of asymmetric information held on the part of lenders/investors together with positive application and search costs (including psychological costs) for finance. On this basis, policy intervention or industry practice rectifying this problem should aim at reducing large information asymmetries, significant application and search costs, or both (Freel et al. 2012).

Unfortunately, both problems are endemic among SMEs, with only better credit scoring models for debt and business enterprise ascertainment processes for equity likely to overcome deficiencies in the former. As to the latter, while application and search costs conceivably decrease in a more competitive and efficient SME financing sector, overcoming the psychic costs in the form of the discouragement experienced by the owners and managers of SMEs may be more difficult. These could conceivably encompass areas as diverse as ex post counselling as to the reasons for negative finance seeking outcomes by providers to the provision of pre-application advice and guidance for future applications.

However, we should also note several limitations of this study. First, while we include profitability, firm age, and business strategy in our analysis, data limitations preclude us from directly identifying measures of relationship financing. For example, Chakravarty and Yilmazer (2009) conclude that banking relationships, as measured by the length and number of pre-existing loans, can affect whether a SME applies for a loan. A more direct measure of relationship financing could also better control for finance worthiness. Second, our data are also limited in that our measure of profitability is relative and subjective and not in terms of dollars. This is problematic in that it would be far better to set a threshold for finance worthiness by industry and/or firm size.

Finally, once again data limitations mean that we measure firm age by category not continuously, and the latter would certainly be more informative and less restrictive when interpreting the estimated relationships. Likewise, there are many other firm conditions and behaviours common among SMEs that can also affect finance seeking and outcomes, most notably franchising, that we were unable to specify fully in our analysis. Future research should then aim to employ a more comprehensive set of variables as controls for finance seeking and worthiness. 


\section{References}

Amini S, Keasey K and Hudson R (2013) The equity funding of smaller growing companies and regional stock exchange. International Small Business Journal 30(8): 832-849.

Ang J (1991) Small business uniqueness and the theory of financial management. Journal of Small Business Finance 37(1): 219-226.

Balakrishnan S and Fox I (1993) Asset specificity, firm heterogeneity and capital structure. Strategic Management Journal 14(1): 3-16.

Barron A, Hulten P and Hudson S (2010) The financial crisis and the gathering of political intelligence: A crosscountry comparison of SMEs in France, Sweden and the UK. International Small Business Journal 30(4): 345-366.

Beck T, Demirguc-Kunt A and Maksimovic V (2005) Financial and legal constraints to firm growth: Does size matter? Journal of Finance 60(1): 137-177.

Beck T, Demirguc-Kunt A and Maksimovic, V. (2008) Financing patterns around the world: Are small firms different? Journal of Financial Economics 89(3): 467-487.

Bergemann D and Hege U (2003) The value of benchmarking. In: McCahery J and Rennenboog L (eds.) Venture Capital Contracting and the Valuation of High Tech Firms. Oxford: Oxford University Press, 83107.

Berger AN and Schaeck K (2011) Small and medium-sized enterprises, bank relationship strength, and the use of venture capital. Journal of Money, Credit and Banking 43(2-3): 461-490.

Berger AN and Udell GF (2006) A more complete conceptual framework for SME finance. Journal of Banking and Finance 30(11): 2945-2966.

Berger AN and Udell GF (1998) The economics of small business finance: The roles of private equity and debt markets in the financial growth cycle. Journal of Banking and Finance 22(6-8): 613-673.

Bhaird CMA and Lucey B (2010) Determinants of capital structure in Irish SMEs. Small Business Economics 35(3): 357-375.

Blumberg BF and Letterie WA (2008) Business starters and credit rationing. Small Business Economics 30(1), 187-200.

Brown M, Ongena S, Popov A, and Yesin P (2011) Who needs credit and who gets credit in Eastern Europe? Economic Policy Journal 26(65): 93-130.

Caneghem TV and Campenhout GV (2010) Quantity and quality of information and SME financial structure. Small Business Finance 39(2): 341-358.

Cavalluzzo KS, Cavalluzzo LC and Wolken JD (2002) Competition, small business financing, and discrimination: Evidence from a new survey. Journal of Business 75(4): 641-679.

Chakravarty S and Yilmazer T (2009) A multistage model of loans and the role of relationships. Financial Management 38(4): 781-816.

Cole RA (2011) What do we know about the capital structure of privately held U.S firms? Evidence from the Survey of Small Business Finance. Available at http://ssrn.com/abstract=1013085.

Cole RA (2010) Who needs credit and who gets credit? Evidence from the Surveys of Small Business Finance. Available at SSRN: http://ssrn.com/abstract=1131064.

Cornelli F and Yosha O (2003) Stage financing and the role of convertible securities. Review of Economic Studies 70(1): 1-32.

Cowling M, Liu W and Ledger A (2012) Small business financing in the UK before and during the current financial crisis. International Small Business Journal 30(7): 778-800.

Dahiya S and Ray K (2012) Staged investments in entrepreneurial financing. Journal of Corporate Finance 18(5): 1193-1216.

Daskalakis N and Psillaki M (2008) Do country or firm factors explain capital structure? Evidence from SMEs in France and Greece. Applied Financial Economics 18(1): 87-97.

Del-Palacio I, Zhang XT and Sole F (2012) The capital gap for small technology companies: Public venture capital to the rescue? Small Business Economics 38(3): 283-301.

Degryse H, Goeij PD and Kappert P (2010) The impact of firm and industry characteristics on small firms' capital structure. Small Business Economics 38(4): 431-447.

Doern R (2009) Investigating barriers to SME growth and development in transition environments, International Small Business Journal 27(3): 275-305.

Fama, E. F., \& French, K. R (2002) Testing trade-off and pecking order predictions about dividends and debt, Review of Financial Studies, 15(1): 1-33.

Freel M, Carter S, Tagg S and Mason C (2012) The latent demand for bank debt: Characterizing 'discouraged borrowers'. Small Business Economics 38(4), 399-418.

Garcia-Teruel P and Martinez-Solano P (2007) Short-term debt in Spanish SMEs. International Small Business Journal 25(6): 579-602. 
Guiso L and Minetti R (2010) The structure of multiple credit relationships: Evidence from U.S firms. Journal of Money, Credit and Banking 42(6): 1037-1071.

Heyman, D., Deloof, M., \& Ooghe, H (2008) The financial structure of private held Belgian firms. Small Business Economics 30: 301-313.

Hamelin A (2011) Small business groups enhance performance and promote stability, not expropriation. Evidence from French SMEs. Journal of Banking and Finance 35(3): 613-626.

Heckman JJ (1976) The common structure of statistical models of truncation, sample selection and limited dependent variables and a simple estimator for such models. Annals of Economic and Social Measurement 5(4): 475-492.

Heckman JJ (1979) Sample bias as a specification error. Econometrica 47(1): 153-161.

Hernandez-Canovas G and Koeter-Kant J (2008) Debt maturity and relationship lending. International Small Business Journal 26(5): 595-617.

Iturralde T, Maseda A and San-Jose L (2010) Empirical evidence of banking relationships for Spanish SMEs. International Small Business Journal 28(3): 274-295.

Jappelli T (1990) Who is credit constrained in the U.S. economy? The Quarterly Journal of Economics 105(1): 219-234.

Jensen MC and Meckling WH (1976) Theory of the firm: Managerial behaviour, agency costs, and ownership structure. Journal of Financial Economics 3(4): 305-360.

Kon Y and Storey DJ (2003) A theory of discouraged borrowers. Small Business Economics 21(1): 31-49.

Levenson A and Willard K (2000) Do firms get the financing they want? Measuring credit rationing experienced by small businesses in the U.S. Small Business Economics 14(1): 83-94.

Lopez-Gracia J and Sogorb-Mira F (2008) Testing trade-off and pecking order theories financing SMEs. Small Business Economics 31(2): 117-136.

Moro A, Fink M and Kautonen T (2012) How do banks asses entrepreneurial competence: The role of voluntary information disclosure. International Small Business Journal. Available at doi: 10.1177/0266242612458444.

Neher DV (1999) Staged financing: An agency perspective. Review of Economic Studies 66(2): 255-274.

Newman A, Gunessee S and Hilton B (2010) Applicability of financial theories of capital structure to the Chinese cultural context: A study of privately owned SMEs. International Small Business Journal 30(1): 65-83.

Pettit R and Singer R (1985) Small business finance: A research agenda. Financial Management 14(3): 47-60.

Psillaki M and Daskalakis N (2009) Are the determinants of capital structure country or firm specific? Small Business Economics 33(3): 319-333.

Riding A, Orser BJ, Spence M and Belanger B (2012) Financing new venture exporters. Small Business Economics 38(2): 147-163.

Romano CA, Tanewski GA and Smyrnios KX (2000) Capital structure decision making: A model for family business. Journal of Business Venturing 16(3): 285-310.

Stratling R, Wijbena F and Graham D (2013) Applicability of financial theories of capital structure to the Chinese cultural context: A study of privately owned SMEs. International Small Business Journal 30(8): 811-831.

Van der Wijst D (1989) Financial Structure in Small Business: Theory, Tests, and Applications. Berlin: Springer-Verlag.

Vos E, Yeh AJY, Carter S and Tagg S (2007) The happy story of small business financing, Journal of Banking and Finance 31(9): 2648-2672.

Zahra SA, Neubaum D and Huse, M (2000) Entrepreneurship in medium-size companies: Exploring the effects ownership and governance systems. Journal of Management 26(5): 947-976. 
Figure I. SME finance seeking and outcomes

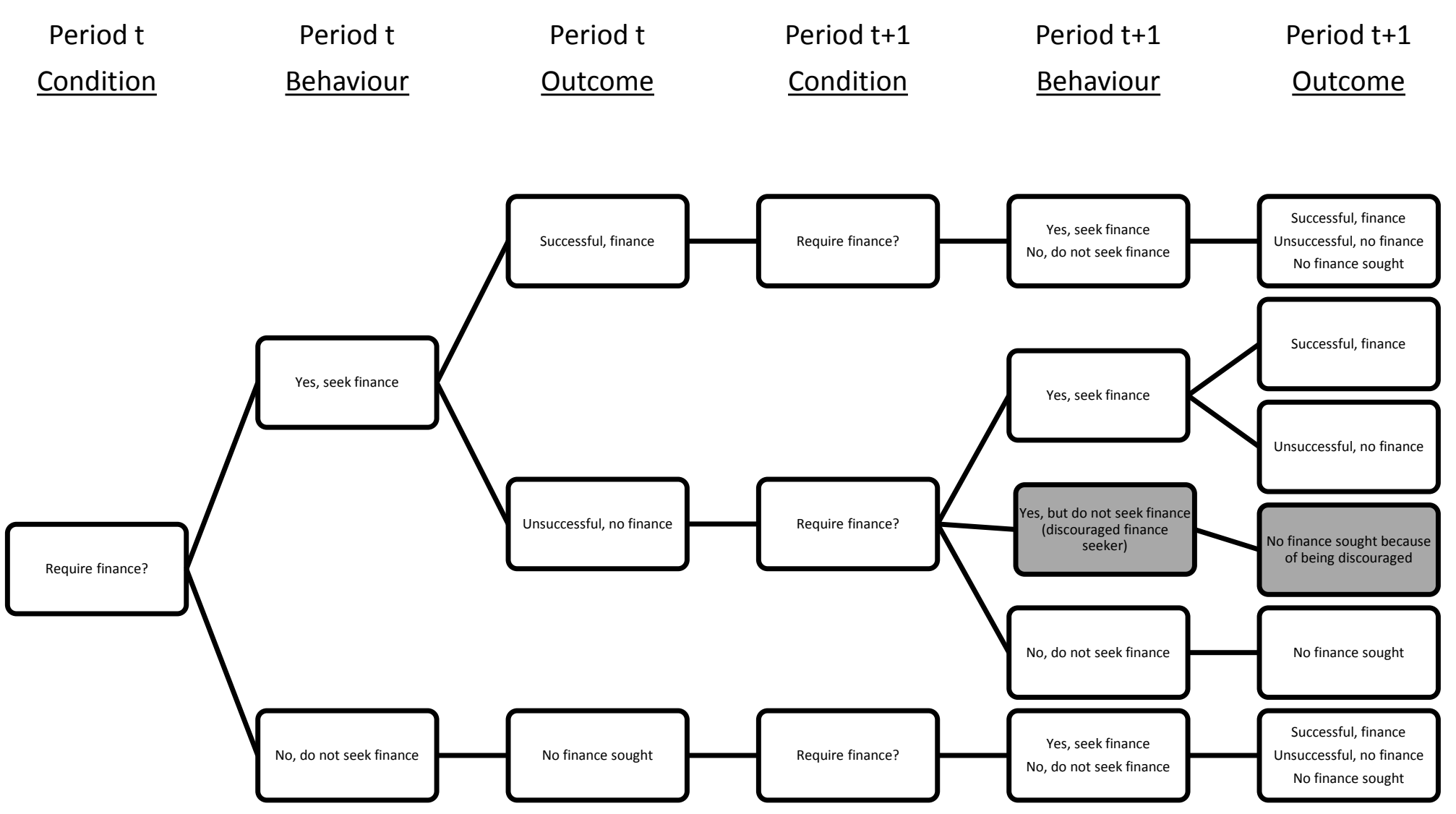


Table I. Variable definitions and statistics

\begin{tabular}{|c|c|c|c|c|c|c|c|c|}
\hline \multirow{2}{*}{ Variables } & & \multirow{2}{*}{ Definition } & \multicolumn{3}{|c|}{ Mean } & \multicolumn{3}{|c|}{ Std. dev. } \\
\hline & & & Year $t$ & Year $t+1$ & Year $t+2$ & Year $t$ & Year $t+1$ & Year $t+2$ \\
\hline \multirow{6}{*}{ 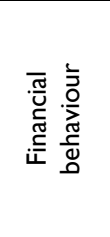 } & Applied for debt and/or equity & Equals one if sought debt and/or equity; zero otherwise. & 0.410 & 0.192 & 0.203 & 0.491 & 0.392 & 0.404 \\
\hline & Applied for debt & Equals one if sought debt; zero otherwise. & 0.384 & 0.185 & 0.192 & 0.481 & 0.372 & 0.293 \\
\hline & Applied for equity & Equals one if sought equity; zero otherwise. & 0.091 & 0.030 & 0.031 & 0.293 & 0.178 & 0.182 \\
\hline & Denied debt/equity & Equals one if debt/equity sought but unavailable; zero otherwise. & 0.120 & 0.131 & 0.137 & 0.182 & 0.147 & 0.153 \\
\hline & Denied debt & Equals one if debt sought but unavailable; zero otherwise. & 0.109 & 0.115 & 0.116 & 0.134 & 0.150 & 0.176 \\
\hline & Denied equity & Equals one if equity sought but unavailable; zero otherwise. & 0.331 & 0.382 & 0.386 & 0.413 & 0.529 & 0.531 \\
\hline \multirow{6}{*}{ 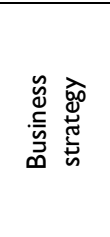 } & Financial focus & Equals one if focus is on financial measures; zero otherwise. & 0.473 & 0.402 & 0.423 & 0.504 & 0.501 & 0.493 \\
\hline & Cost focus & Equals one if focus is on cost measures; zero otherwise. & 0.403 & 0.342 & 0.333 & 0.492 & 0.474 & $0.47 \mathrm{I}$ \\
\hline & Operational focus & Equals one if focus is on operational measures; zero otherwise. & 0.293 & 0.232 & 0.233 & 0.454 & 0.421 & 0.423 \\
\hline & Quality focus & Equals one if focus is on quality measures; zero otherwise. & 0.343 & 0.373 & 0.391 & 0.474 & $0.48 I$ & 0.493 \\
\hline & Innovation focus & Equals one if focus is on innovation measures; zero otherwise. & 0.212 & 0.131 & 0.123 & $0.41 \mathrm{I}$ & 0.342 & 0.331 \\
\hline & Human resource focus & Equals one if focus is human resource measures; zero otherwise. & 0.214 & 0.172 & 0.163 & 0.412 & 0.373 & 0.371 \\
\hline \multirow{11}{*}{ 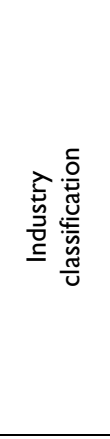 } & Agriculture & Equals one if in agriculture; zero otherwise. & 0.242 & 0.242 & 0.242 & 0.423 & 0.423 & 0.424 \\
\hline & Mining & Equals one if in mining; zero otherwise. & 0.042 & 0.042 & 0.042 & 0.201 & 0.192 & 0.201 \\
\hline & Manufacturing & Equals one if in manufacturing; zero otherwise. & 0.162 & 0.162 & 0.163 & 0.373 & 0.373 & 0.372 \\
\hline & Construction & Equals one if in construction; zero otherwise. & 0.052 & 0.053 & 0.052 & 0.221 & 0.221 & 0.223 \\
\hline & Wholesale trade & Equals one if in wholesale trade; zero otherwise. & 0.103 & 0.103 & 0.103 & 0.302 & 0.303 & 0.302 \\
\hline & Retail trade & Equals one if in retail trade; zero otherwise. & 0.062 & 0.063 & 0.064 & 0.251 & 0.252 & 0.241 \\
\hline & Tourism & Equals one if in accommodation and restaurant; zero otherwise. & 0.073 & 0.073 & 0.073 & 0.253 & 0.253 & 0.252 \\
\hline & Transport & Equals one if in transport; zero otherwise. & 0.062 & 0.062 & 0.062 & 0.241 & 0.242 & 0.242 \\
\hline & Communication & Equals one if in communication services; zero otherwise. & 0.052 & 0.052 & 0.052 & 0.213 & 0.213 & 0.213 \\
\hline & Property & Equals one if in property; zero otherwise. & 0.062 & 0.061 & 0.053 & 0.232 & 0.232 & 0.221 \\
\hline & Culture and recreation & Equals one if in cultural and recreation; zero otherwise. & 0.053 & 0.051 & 0.052 & 0.223 & 0.223 & 0.223 \\
\hline \multirow{8}{*}{ 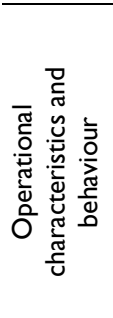 } & Size & Total sales in thousands of dollars & 2678 & 3035 & - & 8707 & 10426 & - \\
\hline & Operating $<5$ years & Equals one if in operation for less than 5 years; zero otherwise. & 0.301 & 0.282 & 0.271 & 0.462 & 0.451 & 0.453 \\
\hline & Operating $10-20$ years & Equals one if in operation for 10 to 20 years; zero otherwise. & 0.263 & 0.271 & 0.271 & 0.442 & 0.443 & 0.443 \\
\hline & Operating $>20$ years & Equals one if in operation for more than 20 years; zero otherwise. & 0.233 & 0.243 & 0.254 & 0.421 & 0.432 & 0.432 \\
\hline & New processes & Equal one if recently introduced new or improved processes; zero otherwise. & 0.262 & 0.363 & 0.311 & 0.443 & 0.483 & 0.462 \\
\hline & Profitability & Equals one if considered more profitable than its competitors; zero otherwise. & 0.124 & 0.322 & 0.301 & 0.332 & 0.471 & 0.462 \\
\hline & Foreign ownership & Equals one if had any foreign ownership; zero otherwise. & 0.041 & 0.041 & 0.042 & 0.201 & 0.192 & 0.202 \\
\hline & Government assistance & Equals one if received any government financial assistance; zero otherwise. & 0.162 & 0.144 & 0.181 & 0.352 & 0.372 & 0.391 \\
\hline
\end{tabular}


Table 2. Determinants of finance seeking

\begin{tabular}{|c|c|c|c|c|c|c|c|c|c|c|c|c|c|c|c|c|c|c|}
\hline \multirow{3}{*}{ Variables } & \multirow{2}{*}{\multicolumn{6}{|c|}{ Debt and/or equity }} & \multirow{2}{*}{\multicolumn{6}{|c|}{$\begin{array}{c}\text { Year } t+2(2007) \\
\text { Debt }\end{array}$}} & \multirow{2}{*}{\multicolumn{6}{|c|}{ Equity }} \\
\hline & & & & & & & & & & & & & & & & & & \\
\hline & Coef. & SE & ME & Coef. & SE & ME & Coef. & SE & ME & Coef. & SE & ME & Coef. & SE & ME & Coef. & SE & ME \\
\hline Denied finance in year $t$ & & & & $-1.072 * * *$ & 0.274 & -0.142 & & & & $-1.197 * * *$ & 0.275 & -0.164 & & & & $-1.07 \mid * *$ & 0.429 & -0.032 \\
\hline Denied finance in year $t+1$ & $-1.178 * * *$ & 0.761 & -0.165 & $-1.026 *$ & 0.713 & -0.148 & $-1.825 * *$ & 0.849 & -0.253 & $-1.627 * *$ & 0.838 & -0.223 & $-2.115 * * *$ & 0.805 & -0.064 & $-1.955 * *$ & 0.827 & -0.059 \\
\hline Constant & $-4.618 * * *$ & 0.971 & & $-3.692 * * *$ & 0.004 & & $-3.994 * * *$ & 1.044 & & $-2.993 * * *$ & 1.063 & & $-4.094 * *$ & 1.658 & & $-3.103 *$ & 1.724 & \\
\hline Financial focus & $0.299 *$ & 0.168 & 0.042 & $0.297 *$ & 0.169 & 0.041 & $0.286 *$ & 0.168 & 0.039 & $0.285 *$ & 0.170 & 0.039 & -0.055 & 0.366 & & -0.067 & 0.368 & \\
\hline Cost focus & 0.092 & 0.175 & & 0.089 & 0.176 & & 0.153 & 0.175 & & 0.150 & 0.176 & & 0.201 & 0.375 & & 0.214 & 0.377 & \\
\hline Operational focus & 0.267 & 0.179 & & 0.256 & 0.181 & & 0.279 & 0.178 & & 0.266 & 0.180 & & -0.332 & 0.394 & & -0.342 & 0.397 & \\
\hline Quality focus & $-0.278 *$ & 0.161 & -0.039 & $-0.291 *$ & 0.161 & 0.040 & $-0.218 *$ & 0.128 & -0.030 & $-0.231 *$ & 0.131 & -0.032 & -0.048 & 0.336 & & -0.068 & 0.340 & \\
\hline Innovation focus & 0.196 & 0.193 & & 0.196 & 0.193 & & 0.191 & 0.192 & & 0.191 & 0.194 & & 0.103 & 0.391 & & 0.112 & 0.392 & \\
\hline Human resource focus & -0.063 & 0.190 & & -0.053 & 0.191 & & -0.100 & 0.190 & & -0.090 & 0.192 & & -0.186 & 0.415 & & -0.201 & 0.417 & \\
\hline Agriculture & $0.959 * * *$ & 0.319 & 0.137 & $0.97 \mid * * *$ & 0.322 & 0.134 & $0.975 * * *$ & 0.318 & 0.136 & $0.990 * * *$ & 0.322 & 0.136 & 1.448 & 1.105 & & 1.443 & 1.053 & \\
\hline Mining & $0.747 *$ & 0.420 & 0.094 & $0.759 *$ & 0.423 & 0.095 & $0.823 * *$ & 0.417 & 0.114 & $0.759 *$ & 0.423 & 0.104 & $2.994 * * *$ & 1.078 & 0.091 & $2.968 * * *$ & 1.081 & 0.089 \\
\hline Manufacturing & 0.493 & 0.329 & & 0.482 & 0.333 & & 0.493 & 0.329 & & 0.482 & 0.333 & & 1.332 & 1.059 & & 1.330 & 1.059 & \\
\hline Construction & 0.445 & 0.404 & & 0.402 & 0.408 & & 0.379 & 0.407 & & 0.402 & 0.409 & & 0.302 & 1.432 & & 0.336 & $\mathrm{I}, 432$ & \\
\hline Wholesale trade & 0.247 & 0.359 & & 0.214 & 0.364 & & 0.215 & 0.360 & & 0.214 & 0.364 & & 0.800 & 1.142 & & 0.817 & 1.142 & \\
\hline Retail trade & 0.429 & 0.384 & & 0.480 & 0.387 & & 0.424 & 0.384 & & 0.480 & 0.387 & & 0.715 & 1.240 & & 0.799 & 1.242 & \\
\hline Tourism & 0.007 & 0.405 & & -0.008 & 0.409 & & -0.014 & 0.405 & & -0.008 & 0.409 & & 1.696 & 1.112 & & 1,713 & $\mathrm{I}, \mathrm{II} 4$ & \\
\hline Transport & 0.414 & 0.387 & & 0.429 & 0.391 & & 0.423 & 0.387 & & 0.429 & 0.391 & & 1.174 & 1.177 & & 1.204 & 1.117 & \\
\hline Communication services & -0.058 & 0.437 & & -0.230 & 0.459 & & -0.304 & 0.455 & & -0.231 & 0.459 & & 1.165 & 1.186 & & 1,197 & 1.200 & \\
\hline Property & 0.535 & 0.392 & & 0.569 & 0.396 & & 0.539 & 0.392 & & 0.568 & 0.396 & & 0.961 & 1.240 & & 0.971 & $\mathrm{I}, 243$ & \\
\hline Culture and recreation & -0.313 & 0.453 & & -0.320 & 0.458 & & -0.321 & 0.453 & & -0.320 & 0.458 & & 1.308 & 1.172 & & 1.340 & 1.173 & \\
\hline Sales & $0.57 \mid * * *$ & 0.088 & 0.078 & $0.561 * * *$ & 0.089 & 0.078 & $0.568 * * *$ & 0.088 & 0.079 & $0.562 * * *$ & 0.089 & 0.077 & 0.143 & 0.175 & & 0.120 & 0.175 & \\
\hline Operating $<5$ years & 0.224 & 0.183 & & 0.247 & 0.185 & & 0.277 & 0.184 & & 0.247 & 0.185 & & 0.408 & 0.380 & & 0.375 & 0.383 & \\
\hline Operating 10-20 years & -0.092 & 0.182 & & -0.133 & 0.185 & & -0.135 & 0.184 & & -0.133 & 0.185 & & -0.208 & 0.422 & & -0.179 & 0.423 & \\
\hline Operating $>20$ years & -0.207 & 0.188 & & -0.205 & 0.191 & & -0.191 & 0.189 & & -0.205 & 0.190 & & -0.012 & 0.426 & & -0.024 & 0.427 & \\
\hline New processes & $0.865 * * *$ & 0.135 & 0.121 & $0.813 * * *$ & 0.136 & 0.111 & $0.820 * * *$ & 0.135 & 0.114 & $0.813 * * *$ & 0.136 & 0.112 & $1.158 * * *$ & 0.298 & 0.035 & $\mathrm{I} .144 * * *$ & 0.300 & 0.034 \\
\hline Profitability & -0.017 & 0.137 & & 0.114 & 0.138 & & 0.018 & 0.137 & & 0.014 & 0.138 & & -0.200 & 0.297 & & -0.189 & 0.298 & \\
\hline Foreign ownership & $-0.535 *$ & 0.320 & -0.075 & $-0.658 * *$ & 0.332 & -0.090 & $-0.543 *$ & 0.324 & -0.075 & $-0.658 * *$ & 0.332 & -0.090 & 0.637 & 0.488 & & 0.472 & 0.500 & \\
\hline Government assistance & $0.647 * * *$ & 0.146 & 0.091 & $0.624 * * *$ & 0.147 & 0.085 & $0.625 * * *$ & 0.147 & 0.087 & $0.624 * * *$ & 0.147 & 0.086 & $0.568 *$ & 0.312 & 0.017 & $0.562 *$ & 0.312 & 0.017 \\
\hline Obs. & 1834 & & & 1834 & & & 1834 & & & 1834 & & & 1834 & & & 1834 & & \\
\hline LR test & 229.590 & & & 253.860 & & & 235.520 & & & 253.860 & & & 164.5 & & & 169.8 & & \\
\hline Wald test & 220.418 & & & 241.109 & & & 227.231 & & & 243.910 & & & 152.1 & & & 157.2 & & \\
\hline R-squared & 0.129 & & & 0.138 & & & 0.128 & & & 0.138 & & & 0.056 & & & 0.059 & & \\
\hline
\end{tabular}

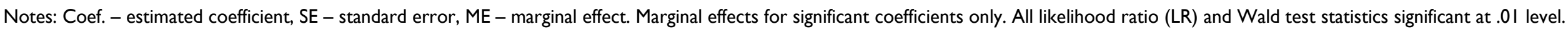

